\title{
COMPARISON OF PROPERTIES OF MWCNT/CARBON FIBRE/ EPOXY LAMINATED COMPOSITES PREPARED BY SOLVENT SPRAYING METHOD
}

\author{
W.A.D. Wan Dalina ${ }^{1}$, M. Mariatti ${ }^{1,2}$, Z. A. Mohd Ishak ${ }^{1,2}$, and A. R. Mohamed $^{3}$ \\ ${ }^{1}$ School of Materials and Mineral Resources Engineering, \\ Universiti Sains Malaysia, Engineering Campus \\ 14300 Nibong Tebal, Pulau Pinang, Malaysia \\ Email: mariatti@usm.my \\ Phone: 604-5995262; Fax: 604-5941011 \\ ${ }^{2}$ Cluster for Polymer Composites, Science and Engineering Research Centre, \\ Universiti Sains Malaysia, Engineering Campus \\ 14300 Nibong Tebal, Pulau Pinang, Malaysia. \\ ${ }^{3}$ School of Chemical Engineering, Universiti Sains Malaysia, \\ Engineering Campus, 14300 Nibong Tebal, Pulau Pinang, Malaysia.
}

\begin{abstract}
The incorporation of multi-walled carbon nanotubes (MWCNT) in laminated composites is believed to improve the mechanical and thermal properties of the composites. However, the nature of the MWCNT, which tend to agglomerate and form into ropes, restricts their dispersion in the composites. MWCNT-filled carbon fibre laminated composite was fabricated via hand lay-up followed by the vacuum bagging technique. MWCNT at different loadings of 0.5 to $1.0 \mathrm{vol} \%$ was dispersed by a solvent spraying method with two different dispersing agents, namely ethanol and Triton $\mathrm{X}$ 100. The flexural and thermal properties of the hybrid laminated composites were investigated. The CF laminated composites filled with 1.0 vol\% of MWCNT dispersed in ethanol possessed better mechanical properties than other hybrid CF composites.
\end{abstract}

Keywords: Carbon fiber; multi-walled carbon nanotubes; flexural properties; thermogravimetry analysis

\section{INTRODUCTION}

Owing to their remarkable mechanical properties as well as low densities, carbon fibre reinforced epoxy composites are extensively chosen for use in engineering applications [1-4]. On the other hand, very active research on CNT over the last decades has revealed the remarkable flexibility of CNTs, their low mass density and large aspect ratio (typically > 1000) [5,6]. The success of carbon nanotubes (CNT) in improving the toughness properties of polymer has attracted increasing interest in their use as an additional reinforcement material in laminated composites [7].Though incorporation of CNTs has been reported to improve the toughness of composites, the fabrication of these laminated composites is constrained by the agglomeration of CNTs [8]. CNTs have a high tendency to form into bundles and ropes in the matrix due to their strong inter tube van der Waals forces $[8,9]$. The CNTs agglomeration limits the load transfer process from the matrix to the CNTs; therefore the effective dispersion of CNTs in the matrix is vital [8]. In order to improve CNTs dispersion on the reinforcement, a solvent 
spraying method [2] was chosen, by which the CNTs were sprayed onto the fabric prior to hand lay-up. This study intends to fabricate hybrid laminated composites of carbon fibre (CF)/ epoxy incorporated with multi-walled carbon nanotubes (MWCNT) in the composite system by using the hand lay-up technique, followed by the vacuum bagging technique. The effects of the type of dispersing agents and filler loadings on the flexural and thermal properties of laminated composites were investigated.

\section{EXPERIMENTAL}

\section{Materials}

Carbon fabric type 5-harness satin weave with identical warp and fills yarns of 6000 multi-filament continuous tow was used as reinforcement. The fabric with a linear density of $369.58 \mathrm{~g} / \mathrm{m}^{2}$ was supplied by Fibre Glast Corporation. The D.E.N. 431 epoxy novolac resin and Polyetheramine D230 (supplied by Penchem Industries Sdn. Bhd.) were used as a matrix and curing agent, respectively. A resin and a curing agent, with a ratio of 100 to 32, were used in the study[10]. The MWCNTs used in this study were synthesized by a group of researchers from the Universiti Sains Malaysia. The highly pure MWCNTs (99.8\%), with nearly uniform diameter average of $6.2 \mathrm{~nm} \pm 0.5 \mathrm{~nm}$ (mean \pm standard deviation), were synthesized over magnesia-supported Co-Mo bimetallic catalysts through catalytic chemical vapour deposition [11]. Ethanol and octyl phenol ethoxylate or Triton X - 100 (TX-100) at a concentration of $1 \%$ were used as dispersing agents.

\section{Methodology}

A control sample of 4-ply CF/epoxy (4CF) was prepared using 4 pieces of CF with similar dimensions. The fabric was first weighed to determine the amount of epoxy matrix needed. The amount of epoxy matrix was fixed at $40 \mathrm{vol} \%$. The predetermined epoxy resin was mixed with curing agent at a ratio of 100:32. The fabrics were then stacked together by applying the hand lay-up technique followed by the vacuum bagging method. The laminated composite was consolidated for 1 hour, then left overnight to cure before being subjected to a curing and post-curing process at $100{ }^{\circ} \mathrm{C}$ $(1 \mathrm{hr})$ and $125^{\circ} \mathrm{C}(3 \mathrm{hrs})$, respectively. The same procedures were repeated in preparing 5-ply CF/epoxy laminated composite (5CF). MWCNT-filled laminated composites were prepared by first incorporating MWCNT into the composites by the spraying method prior to the hand lay-up and vacuum bagging technique. The predetermined mass of MWCNT (0.5 vol\%) was first ultrasonicated in $30 \mathrm{ml}$ of ethanol in a cold bath for about 30 minutes. The prepared mixture was then sprayed onto 4 pieces of $\mathrm{CF}$ with the same dimensions. The fabrics were then left to dry at room temperature for about 4 hours to allow evaporation of ethanol. The dried fabrics were stacked up together with 40 vol\% of epoxy matrix. The vacuum bagging, curing and post-curing process were carried out as mentioned previously. Samples with 1.0 and $1.5 \mathrm{vol} \%$ of MWCNT were dispersed in 60 and $90 \mathrm{ml}$ of ethanol respectively. The same procedure was applied to prepare samples which used TX-100 as dispersing agent. The sample designations are shown in Table 1. 
Table 1.Sample designations.

\begin{tabular}{cccccc}
\hline No. & Sample & $\begin{array}{c}\text { No. of } \\
\text { CF layers }\end{array}$ & $\begin{array}{c}\text { Epoxy } \\
(\text { vol \%) }\end{array}$ & $\begin{array}{c}\text { CF } \\
(\text { vol \%) }\end{array}$ & $\begin{array}{c}\text { CNTs } \\
(\text { vol \%) }\end{array}$ \\
\hline 1. & Epoxy & - & 100 & - & - \\
2. & 4CF & 4 & 40 & 60 & - \\
3. & 5CF & 5 & 40 & 60 & - \\
4. & 4CNT E0.5 & 4 & 40 & 59.5 & 0.5 \\
5. & 4CNT E1.0 & 4 & 40 & 59.0 & 1.0 \\
6. & 4CNT E1.5 & 4 & 40 & 58.5 & 1.5 \\
7. & 4CNT T0.5 & 4 & 40 & 59.5 & 0.5 \\
8. & 4CNT T1.0 & 4 & 40 & 59.0 & 1.0 \\
9. & 4CNT T1.5 & 4 & 40 & 58.5 & 1.5 \\
\hline
\end{tabular}

\section{Characterization}

The flexural properties of 5 composites samples were tested according to ASTM D-790 using an INSTRON 5982. The specimens with dimensions $80 \mathrm{~mm}$ long $\times 17 \mathrm{~mm}$ wide $\times 2 \mathrm{~mm}$ thick with a $40 \mathrm{~mm}$ support span were loaded under three-point bending at a cross-head rate of $2 \mathrm{~mm} / \mathrm{min}$ until failure [10]. The density of 6 composite samples with dimensions of $10 \mathrm{~mm} \times 10 \mathrm{~mm}$ was measured using a gravity balance, Precisa 8000 , based on Archimedes' Principle. The average density was calculated[10]. Raw fabric samples sprayed with MWCNT were observed under a scanning electron microscope (SEM), FESEM/Zeiss Supra 35 VP. The thermal stability of the samples was measured through thermogravimetry analysis (TGA) using a Mettler Toledo, TGA/DSC Star ${ }^{\mathrm{e}}$ System Analyzer. A small piece of the selected sample was weighed and heated in a nitrogen environment from ambient temperature to $600{ }^{\circ} \mathrm{C}$ at a heating rate of $10{ }^{\circ} \mathrm{C}$ per $\min$.

\section{RESULTS AND DISCUSSION}

\section{Flexural Properties}

Figure 1 demonstrates the flexural strength and modulus of the unfilled epoxy, the laminated CF composites and MWCNT-filled CF laminated composites. As expected, the flexural strength of $4 \mathrm{CF}$ was $25 \%$ lower than $5 \mathrm{CF}$. This is due to the reduction of the fibre reinforcement that is present in the composite system. It is observed that composites prepared by solvent spraying with TX-100 possessed lower flexural strength than either $4 \mathrm{CF}$ or $5 \mathrm{CF}$. The drop in the flexural strength might be due to the nature of the Triton $X$, which caused the surface between the carbon fabrics to become slippery [12-14]. Conversely, composites prepared by spraying with ethanol show improvements in flexural strength compared to 4CF. In comparison with 5CF, composites incorporated with 0.5 vol\% MWCNT exhibit a flexural strength $5 \%$ higher than 4CF but $22 \%$ lower than $5 \mathrm{CF}$. This observation shows that incorporation of $0.5 \mathrm{vol} \%$ MWCNT increases the flexural strength of 4-ply CF. However, the amount of MWCNT used was insufficient to increase the flexural strength compared to that of 5-ply CF. Incorporation of $1.0 \mathrm{vol} \%$ of MWCNT recorded the most significant improvement in flexural strength compared to both $4 \mathrm{CF}$ and $5 \mathrm{CF}$. These hybrid composites exhibit flexural strength that is $135 \%$ and $75 \%$ higher than $4 \mathrm{CF}$ and $5 \mathrm{CF}$, respectively. On the other hand, addition of a higher 
filler loading of MWCNT (1.5 vol\%) caused a drop in the flexural strength compared to samples incorporated with 1.0 vol\% MWCNT. This drop in flexural strength might be due to agglomeration of the MWCNT, which is observed in the SEM micrographs in Figure 2. Figure 2 shows micrographs of CF sprayed with 1.0 and $1.5 \mathrm{vol} \%$ of MWCNT dispersed by ethanol and TX-100 respectively. From Figure 2(a) - (d), it is proven that the higher filler loading caused MWCNT to agglomerate and thus reduced the flexural modulus. On the other hand, it is found that MWCNT dispersed in TX-100 also shows agglomeration at the higher filler loading.

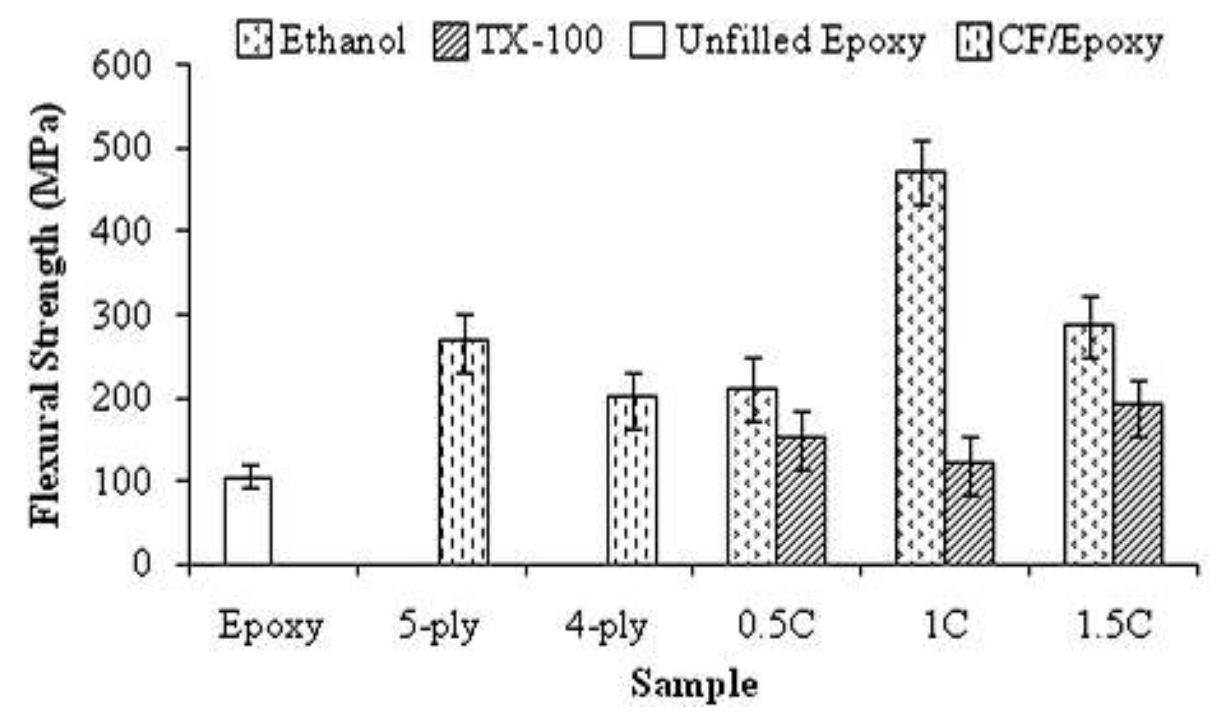

Figure 1. Flexural strength of the unfilled epoxy, the laminated $\mathrm{CF}$ composites and MWCNT-filled CF laminated composites.

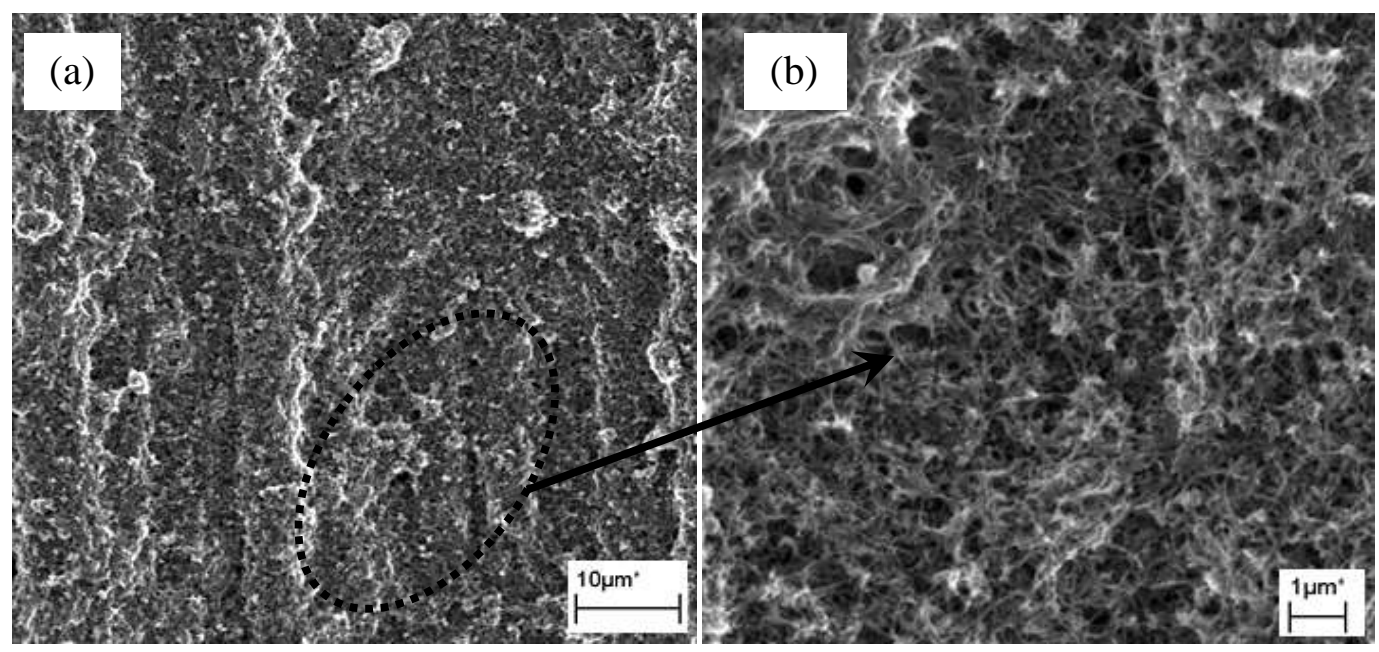

Figure 2. SEM micrographs of CF sprayed with MWCNT at different loadings using different dispersing agents: (a) and (b): 4CNT E1.0; (c) and (d): 4CNT E1.5; (e) and (f): 4CNT T1.0; (g) and (h): 4CNT T1.5. 

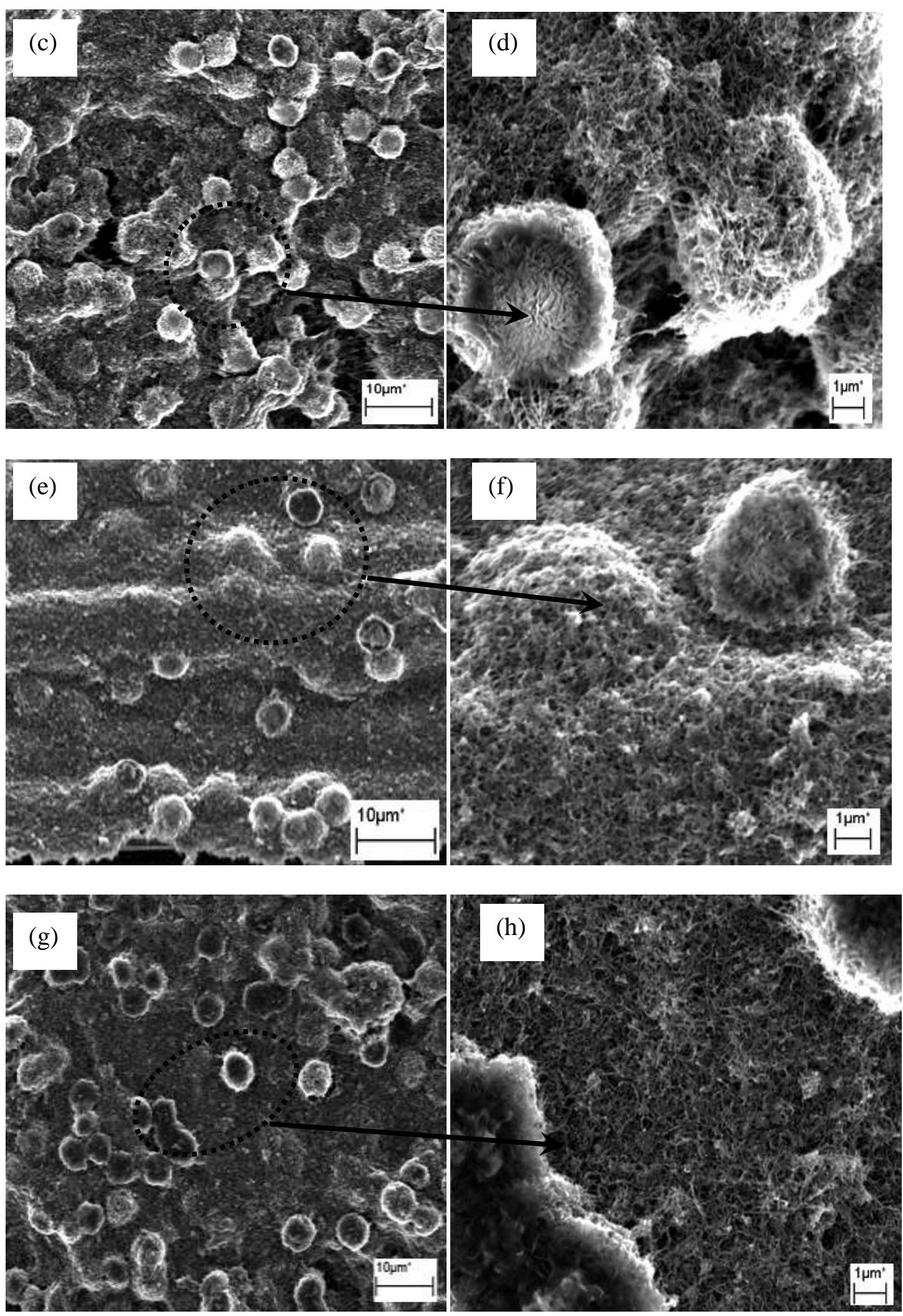

Figure 2.Continued.

Figure 3 demonstrates the flexural strength and modulus of the unfilled epoxy, the laminated CF composites and MWCNT-filled CF laminated composites. Reducing the number of $\mathrm{CF}$ from 5-ply to 4-ply caused a $19 \%$ reduction of flexural modulus. 
Regardless of the vol\% of the filler loading, composites incorporated with MWCNT dispersed by ethanol exhibit higher flexural modulus compared to 4CF. However, in comparison with 5CF, all the hybrid composite samples possessed lower flexural modulus except for composite laminates incorporated with $1.0 \mathrm{vol} \%$ dispersed by ethanol. Comparing the hybrid samples dispersed by ethanol, it seems that the flexural modulus shows a similar trend to that for flexural strength. The flexural modulus dropped at higher filler loading (1.5 vol\%). This observation is supported by the micrographs in Figure 2(a) - (d). The higher filler loading leads to agglomeration of the MWCNT and thus reduces the flexural modulus.

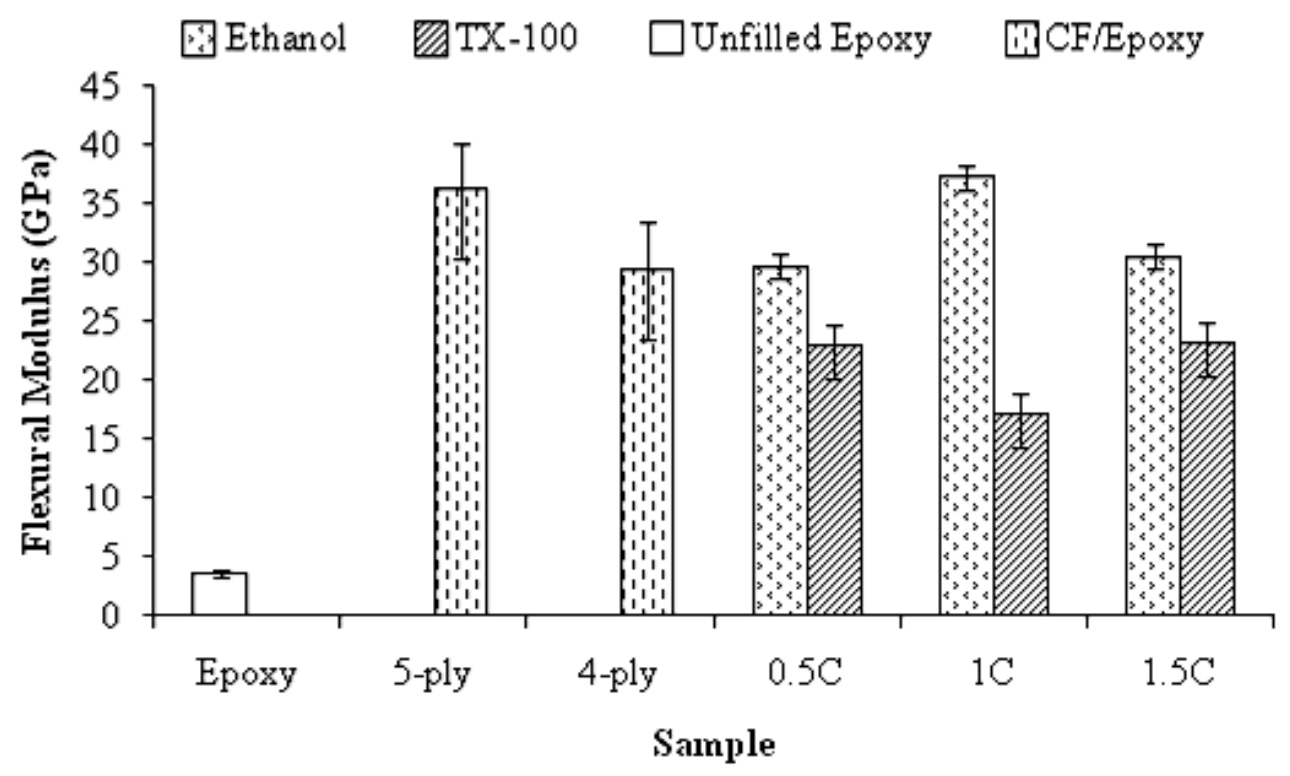

Figure 3. Flexural modulus of the unfilled epoxy, the laminated CF composites and MWCNT-filled CF laminated composites.

\section{Density}

Figure 4 shows the densities of the unfilled epoxy, CF/epoxy laminated composite samples and MWCNT-filled CF/epoxy laminated composites samples. As predicted, the density of 4CF and 4-ply MWCNT-filled CF laminated composites is lower than that of the 5CF samples. Samples incorporated with the same filler loading exhibit almost identical density regardless of the type of dispersing agent. Incorporation of MWCNT into 4-ply CF laminated composites caused the density to increase from 4 to $7 \%$ compared to 4CF. Gajendran and Saraswathy, (2008) also reported that the density of polyaniline-carbon nanotubes composites increased when CNT loading was added in the PANI-CNT system through the solution mixing method [15]. Ogasawara, Moon [16] also reported the same trend when aligned MWCNT was incorporated into epoxy [16]. However, the densities of these laminated composites are 3 to $7 \%$ lower in comparison with the 5-ply $\mathrm{CF}$. This observation indicates that a weight reduction can be achieved in the 4CF system. 


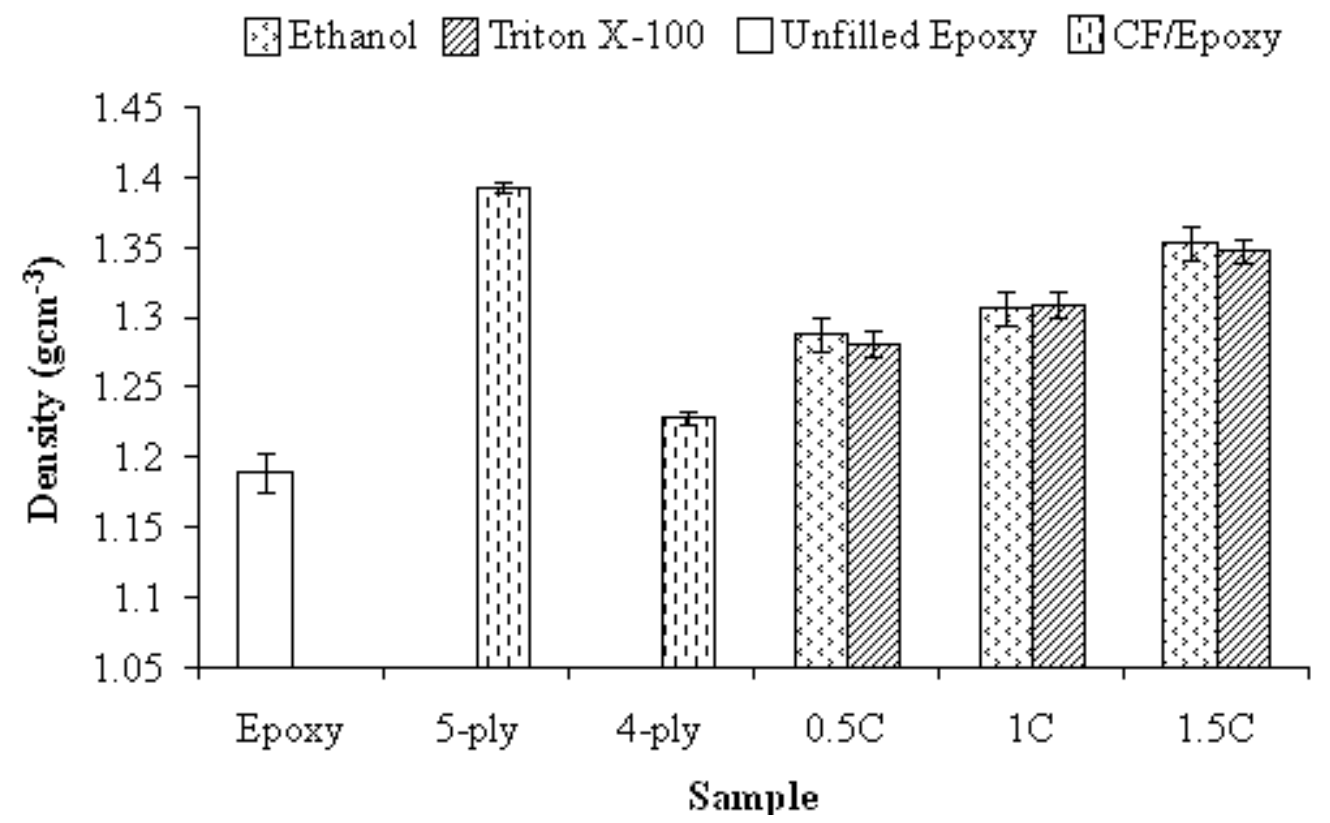

Figure 4. Density of the unfilled epoxy, CF/epoxy laminated composite samples and MWCNT-filled CF/epoxy laminated composites samples.

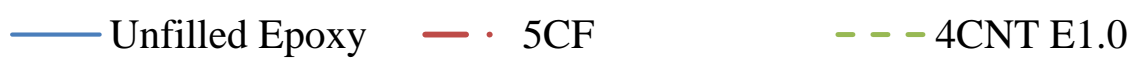

4CNT T1.0 - - 4CNT E1.5

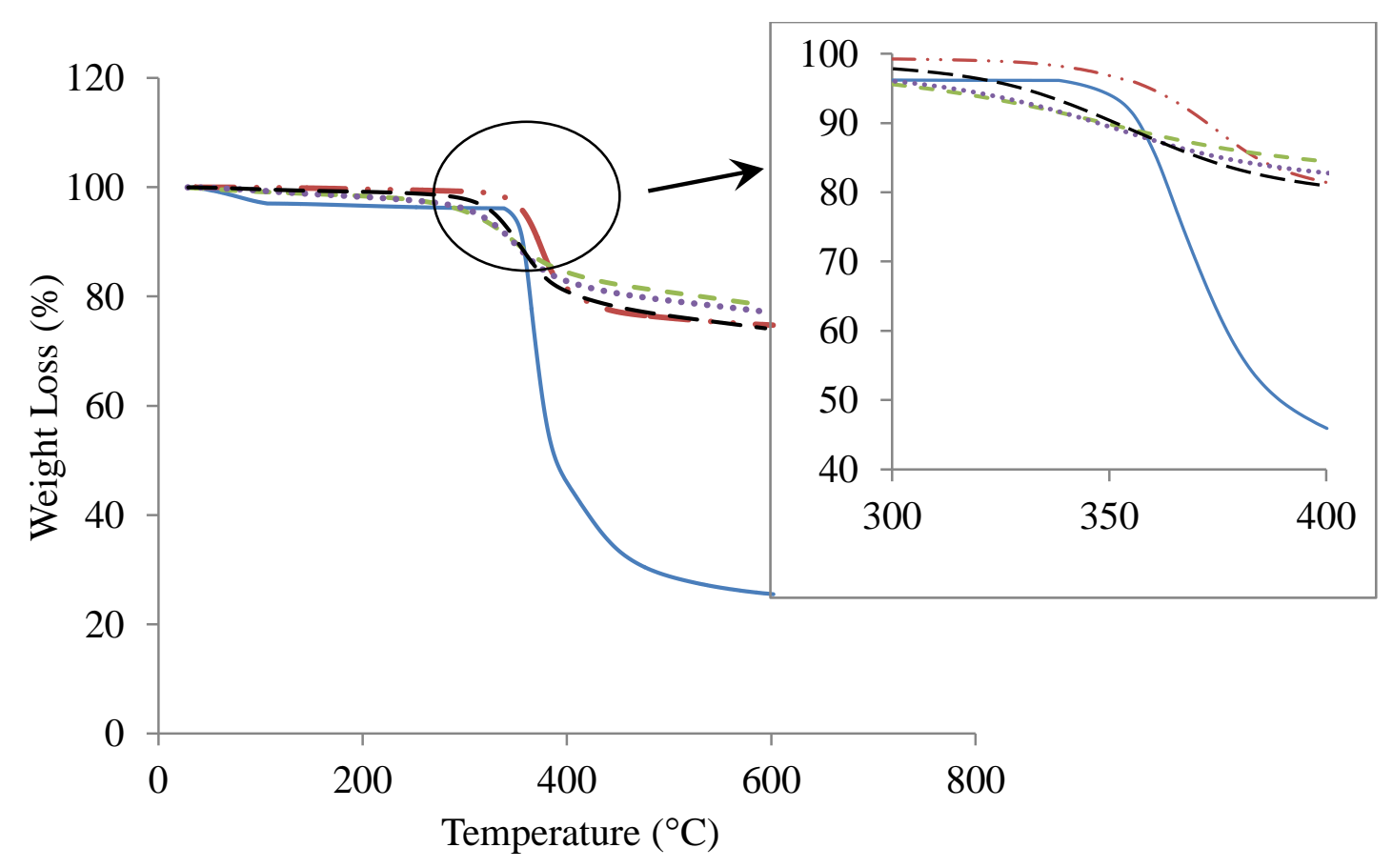

Figure 5. TGA curves of the unfilled epoxy, $5 \mathrm{CF}$ and hybrid composites samples incorporated with 1.0vol\% of MWCNT dispersed by ethanol and TX-100. 


\section{Thermogravimetry Analysis}

Figure 5 shows the TGA curves of the unfilled epoxy, $5 \mathrm{CF}$ and hybrid composites samples incorporated with $1.0 \mathrm{vol} \%$ of MWCNT dispersed by ethanol and TX-100. The TGA curves demonstrate single-step degradation. At $330{ }^{\circ} \mathrm{C}$, the epoxy starts to decompose. 5CF exhibits thermal stability which is slightly higher than the samples incorporated with 1 vol\% of MWCNT. On the other hand, it is observed that the thermal stability of composites incorporated with 1.0 vol\% MWCNT dispersed by ethanol is almost identical to the composites filled with 1.0vol\% MWCNT dispersed by TX-100. Comparing composites CF with MWCNT dispersed with ethanol, it is found that the thermal stability increases with the increasing filler loading. This observation is also in agreement with the observation reported by [16]. The presence of MWCNT produces a structured network layer which acts as a shield that re-emits much of the incident radiation back into the gas phase, thereby decreasing the degradation rate [17].

\section{CONCLUSIONS}

Different types of dispersing agent affect the dispersion of MWCNT differently and thus affect the flexural and thermal properties of the laminated composites incorporated with MWCNT. On the other hand, the amount of filler loading also affects the flexural and thermal properties in different ways. A higher filler loading may lead to agglomeration of the MWCNT and thus have a negative impact on the mechanical properties, whereas the thermal properties of the composites increase with increasing filler loading. From the study, it can be concluded that 4-ply CF laminated composites incorporated with $1.0 \mathrm{vol} \%$ of MWCNT dispersed in ethanol exhibit better flexural properties compared to 5-ply CF. Judging from the discussion, we can conclude that the fabrication of light-weight hybrid composites with better mechanical properties is possible.

\section{ACKNOWLEDGMENTS}

The authors are very gratified to Universiti Sains Malaysia for awarding us with a research grant (Research University Grant, no. 814153) and Ministry of Higher Education (MOHE) for supporting us through MyBrain15 (myPhD) programme, which made this study possible.

\section{REFERENCES}

[1] Mora RJ, Vilatela JJ, Windle AH. Properties of composites of carbon nanotube fibres. Composites Science and Technology. 2009;69:1558-63.

[2] Davis DC, Wilkerson JW, Zhu J, Hadjiev VG. A strategy for improving mechanical properties of a fiber reinforced epoxy composite using functionalized carbon nanotubes. Composites Science and Technology. 2011;71:1089-97.

[3] Agirregomezkorta A, Martínez A, Sánchez-Soto M, Aretxaga G, Sarrionandia M, Aurrekoetxea J. Impact behaviour of carbon fibre reinforced epoxy and nonisothermal cyclic butylene terephthalate composites manufactured by vacuum infusion. Composites Part B: Engineering. 2012;43:2249-56. 
[4] Salleh Z, Yusop MYM, Rosdi MS. Mechanical properties of activated carbon (AC) coir fibers reinforced with epoxy resin. Journal of Mechanical Engineering and Sciences. 2013;5:631-8.

[5] Ma P-C, Siddiqui NA, Marom G, Kim J-K. Dispersion and functionalization of carbon nanotubes for polymer-based nanocomposites: A review. Composites Part A: Applied Science and Manufacturing. 2010;41:1345-67.

[6] Spitalsky Z, Tasis D, Papagelis K, Galiotis C. Carbon nanotube-polymer composites: Chemistry, processing, mechanical and electrical properties. Progress in Polymer Science. 2010;35:357-401.

[7] De Greef N, Gorbatikh L, Lomov SV, Verpoest I. Damage development in woven carbon fiber/epoxy composites modified with carbon nanotubes under tension in the bias direction. Composites Part A: Applied Science and Manufacturing. 2011;42:1635-44.

[8] Zou W, Du Z-j, Liu Y-x, Yang X, Li H-q, Zhang C. Functionalization of MWNTs using polyacryloyl chloride and the properties of CNT-epoxy matrix nanocomposites. Composites Science and Technology. 2008;68:3259-64.

[9] Bose S, Khare RA, Moldenaers P. Assessing the strengths and weaknesses of various types of pre-treatments of carbon nanotubes on the properties of polymer/carbon nanotubes composites: A critical review. Polymer. 2010;51:97593.

[10] Dalina W, Dahalan WA, Mariatti M, Ramlee R, Ishak ZAM, Mohamed AR. Comparison on the Properties of Glass Fiber/MWCNT/Epoxy and Carbon Fiber/MWCNT/Epoxy Composites. Advanced Materials Research. 2014;858:32-9.

[11] Yeoh W-M, Lee K-Y, Chai S-P, Lee K-T, Mohamed AR. Synthesis of high purity multi-walled carbon nanotubes over $\mathrm{Co}-\mathrm{Mo} / \mathrm{MgO}$ catalyst by the catalytic chemical vapor deposition of methane. New Carbon Materials. 2009;24:119-23.

[12] AMSDS. Triton X-100 Surfactant (DOW). 10 Nov 2011 ed. Western Australia: Amber Material Safety Data Sheet 2009. p. 1-5.

[13] Biotechnology SC. Triton X-100 Detergent, Hydrogenated. Material Safety Data Sheet (2009). Texas, USA: Santa Cruz Biotechnology, Inc; 2009.

[14] Sheet CMSD. TRITON X-100 SURFACTANT 31-Jan-2007 ed. Australia: chemwatch; 2007 p. 1-8.

[15] Gajendran P, Saraswathi R. Polyaniline-carbon nanotube composites. Pure and Applied Chemistry. 2008;80:2377-95.

[16] Ogasawara T, Moon S-Y, Inoue Y, Shimamura Y. Mechanical properties of aligned multi-walled carbon nanotube/epoxy composites processed using a hotmelt prepreg method. Composites Science and Technology. 2011;71:1826-33.

[17] Laoutid F, Bonnaud L, Alexandre M, Lopez-Cuesta J-M, Dubois P. New prospects in flame retardant polymer materials: from fundamentals to nanocomposites. Materials Science and Engineering: R: Reports. 2009;63:10025. 